\title{
Aplikasi Gaya Sentrifugal pada Mesin Peniris Serbaguna
}

\author{
Nur Hayati \\ Program Studi Teknik Mesin IST Akprind Yogyakarta \\ E-mail : nurhayati@akprind.ac.id
}

\begin{abstract}
Abstrak
Program pengabdian kepada masyarakat ini bertujuan untuk meningkatkan produktivitas dan nilai ekonomis dari keripik jamur di kelompok tani Pesona Jamur di desa Argosari, kecamatan Sedayu, Bantul. Metode pelaksanaan abdimas ini dimulai dengan pendataan permasalahan pada industry keripik jamur, kemudian dilanjutkan dengan sosialisasi mesin peniris serbaguna. Langkah selanjutnya adalah demo penggunaan mesin peniris dan diakhiri dengan penyerahan alat kepada masyarakat. Hasil abdimas cukup memuaskan, yaitu dapat mengurangi kadar minyak gorengan cukup signifikan. Sampel yang diuji yaitu keripik jamur $5 \mathrm{~kg}$ dan diperoleh keripik jamur sebesar 4,80kg setelah ditiriskan dengan mesin peniris.
\end{abstract}

Kata kunci : gaya sentrifugal,keripik jamur, peniris

\begin{abstract}
This program aims to increase the productivity and economic value of mushroom chips in Pesona Jamur farmer groups in Argosari village, Sedayu district, Bantul. The method of implementing this abdimas begins with data collection of problems in the mushroom chips industry, then continues with the socialization of multipurpose slicing machines. The next step was a demonstration of the use of a slicing machine and ended with handing over the tools to the public. The results of the abdimas are quite satisfying, which can reduce the levels of cooking oil significantly. The samples tested were $5 \mathrm{~kg}$ of mushroom chips and 4.80 $\mathrm{kg}$ of mushroom chips were obtained after being drained using a slicing machine.
\end{abstract}

Keywords: centrigugal force, mushroom chips, peniris

\section{PENDAHULUAN}

Saat ini kemajuan teknologi dalam dunia industri semakin pesat dan canggih, untuk memperbesar suatu proses produksi guna meningkatkan produktifitas dalam dunia industri ini, diperlukan suatu alat bantu berupa mesin produksi tepat guna, efektif, dan efisien.

Setelah melakukan pengamatan pada dunia industri, khususnya industri kecil menengah dalam bidang produksi keripik jamur diketahui bahwa banyak hambatan dan kesulitan dalam proses meniriskan minyak tersebut. Pada proses penggorengan, minyak goreng berfungsi sebagai medium penghantar panas, menambah rasa gurih, menambah nilai gizi dan kalori dalam bahan pangan [1]. Hasil penggorengan biasanya mengandung 5-40\% minyak [2]. Kandungan minyak dari sisa penggorengan sangat berpengaruh pada keawetan hasil produksi keripik. Pengurangan kadar minyak dalam gorengan akan membuat makanan menjadi lebih awet [3]. Selama ini proses penirisan minyak dilakukan secara manual dan menggunakan peralatan seadanya.

Prinsip dasar mesin peniris minyak menggunakan putaran untuk memisahkan minyak dari abon dan keripik. Mesin peniris dirancang menggunakan putaran sentrifugal. Setelah alat dipastikan dalam keadaan siap pakai, kripik hasil penggorengan dimasukan kedalam keranjang peniris. Keranjang peniris adalah 
bagian dari peniris minyak dan merupakan tempat peletakan bahan yang akan ditiriskan. Keranjang peniris ini berbentuk silinder dan terdapat lubang-lubang pada permukaannya. Prinsip kerja dari tabung peniris adalah untuk meniriskan minyak dengan gaya sentrifugal. Gaya sentrifugal ini akan mampu mengeluarkan minyak dari bahan karena adanya gaya yang keluar dari pusat lingkaran [4]. Akibat gaya sentrifugal yang terjadi, didapat tekanan ke segala arah. Kedua hal ini yang akan menyebabkan tegangan pada permukaan keranjang peniris sehingga memudahkan proses penirisan. Selain itu juga ditambahkan kontaktor magnet yang berfungsi sebagai pemutus arus apabila terjadi kelebihan beban [5]. Kontaktor magnet atau saklar magnet merupakan saklar yang bekerja berdasarkan prinsip kemagnetan. Artinya sakelar ini bekerja jika ada gaya kemagnetan pada penarik kontaknya. Magnet berfungsi sebagai penarik dan dan sebagai pelepas kontak-kontaknya dengan bantuan pegas pendorong. Sebuah kontaktor harus mampu mengalirkan dan memutuskan arus dalam keadaan kerja normal.

\section{METODE PENELITIAN}

Pelaksanaan pengabdian kepada masyarakat ini dilaksanakan pada tanggal 14 Januari 2021 di kelompok tani Pesona Jamur yang terletak di desa Argosari, kecamatan Sedayu, Bantul. Tahapan pengabdian dimulai dengan pendataan permasalahan dengan pendataan permasalahan pada industry keripik jamur, kemudian dilanjutkan dengan sosialisasi mesin peniris serbaguna. Langkah selanjutnya adalah demo penggunaan mesin peniris dan diakhiri dengan penyerahan alat kepada masyarakat.

Diagram alir pengabdian kepada masyarakat ini ditunjukkan oleh gambar berikut : 


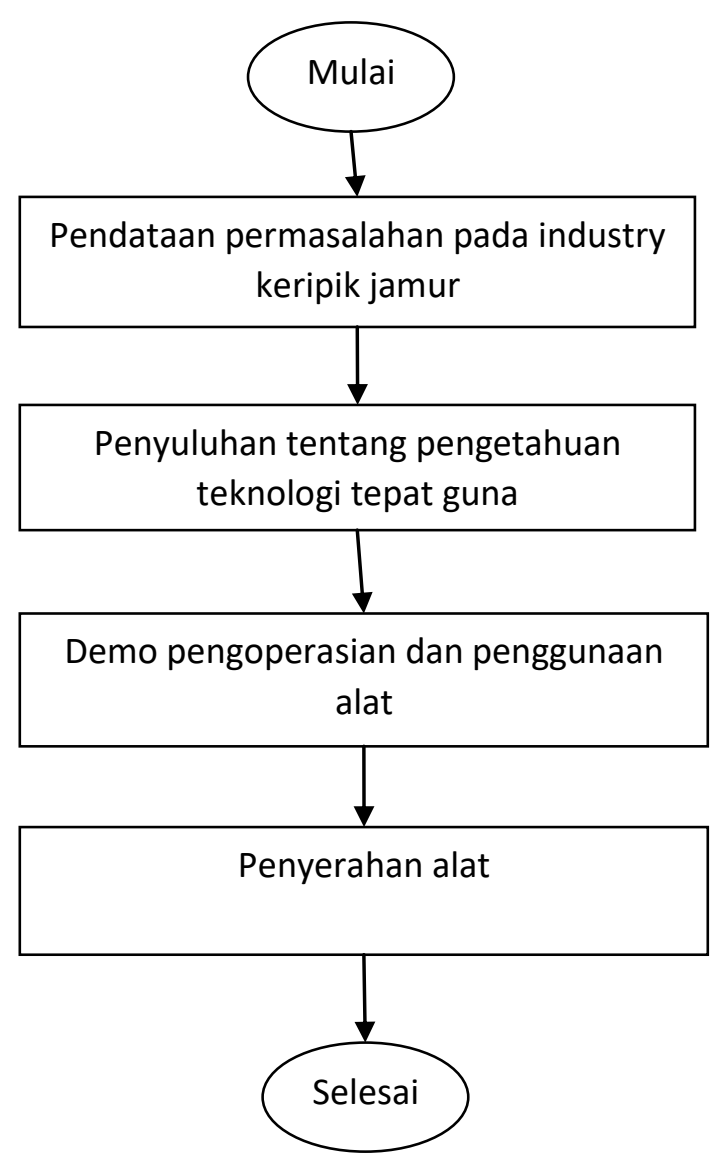

Gambar 1 Diagram Alir Penelitian

\section{HASIL DAN PEMBAHASAN}

Kegiatan pelatihan diawali dengan penyuluhan tentang pengetahuan teknologi tepat guna yaitu alat peniris minyak, diawali dengan teori singkat alat peniris minyak dilanjutkan cara pengoperasian alat. Alat peniris minyak ini menggunakan daya sebesar 169 Watt [5]. Adapun bagian-bagian alat peniris minyak ditunjukkan oleh gambar berikut : 

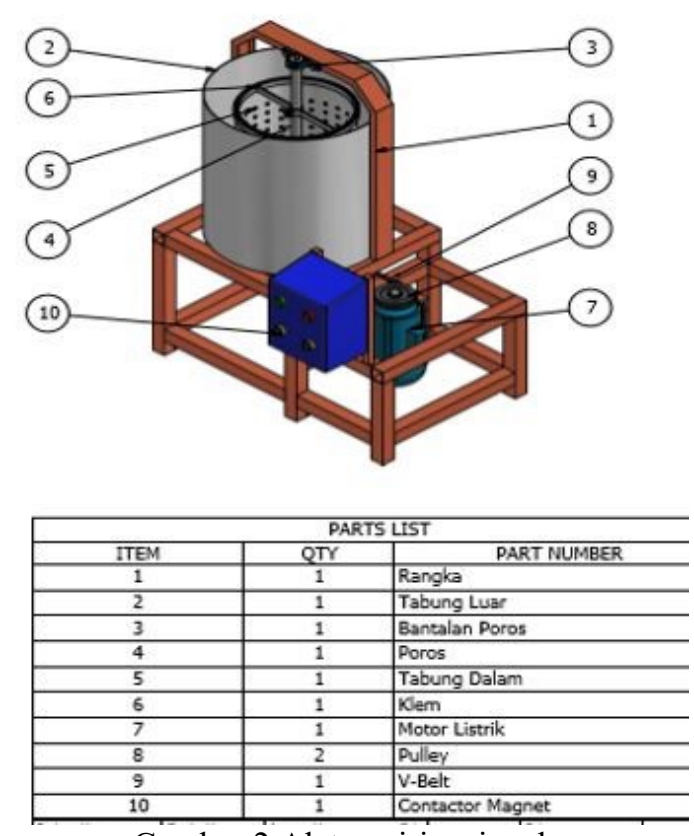

Gambar 2 Alat peniris minyak

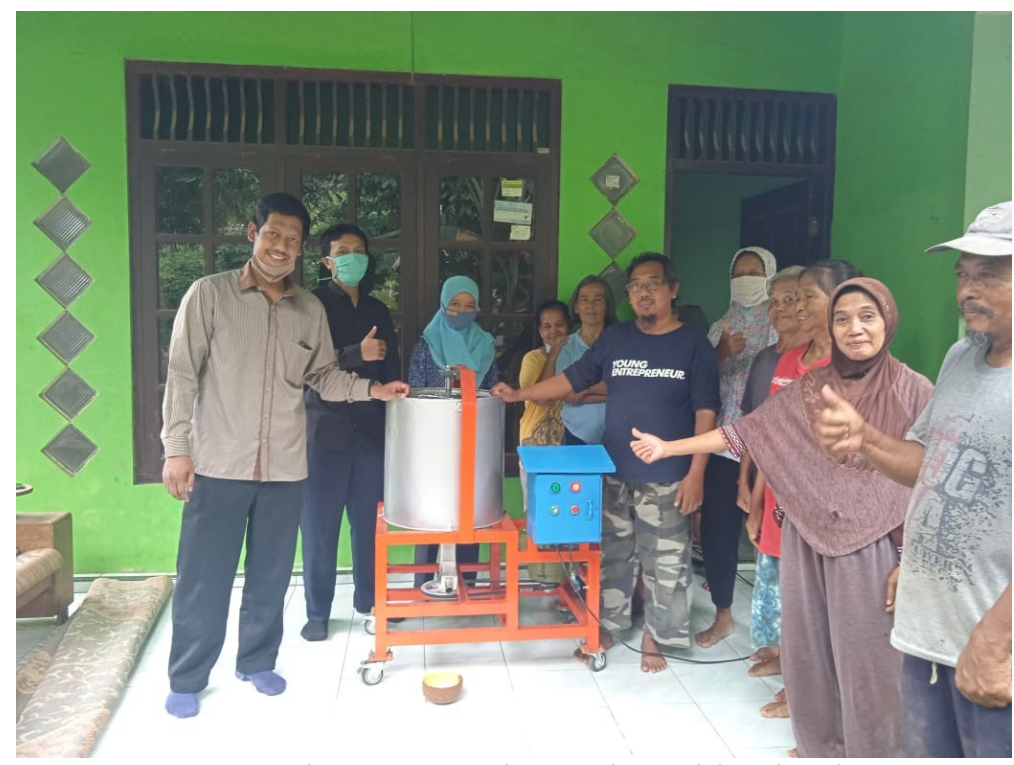

Gambar 3 Pengenalan mesin peniris minyak

Setelah proses penyuluhan tentang teknologi tepat guna, yaitu pengenalan mesin peniris minyak, langkah selanjutnya adalah demo pengoperasian mesin peniris. Sampel yang digunakan adalah keripik jamur (setelah digoreng dan ditiriskan manual) seberat $5 \mathrm{~kg}$.

Proses penirisan dilakukan dengan langkah-langkah sebagai berikut :

1. Masukan makanan ke dalam tabung dengan tertata rapi.

2. Tekan tombol on sehingga lampu indicator hijau menyala.

3. Setelah tabung berputar tunggu 3-7 menit.

4. Siapkan wadah untuk menampung minyak yang sudah ditiriskan

5. Setelah itu matikan mesin sehingga lampu indicator merah menyala

6. Ambil makanan yang sudah ditiriskan. 
7. Bersihkan tabung menggunakan air bersih.

8. Selesai.

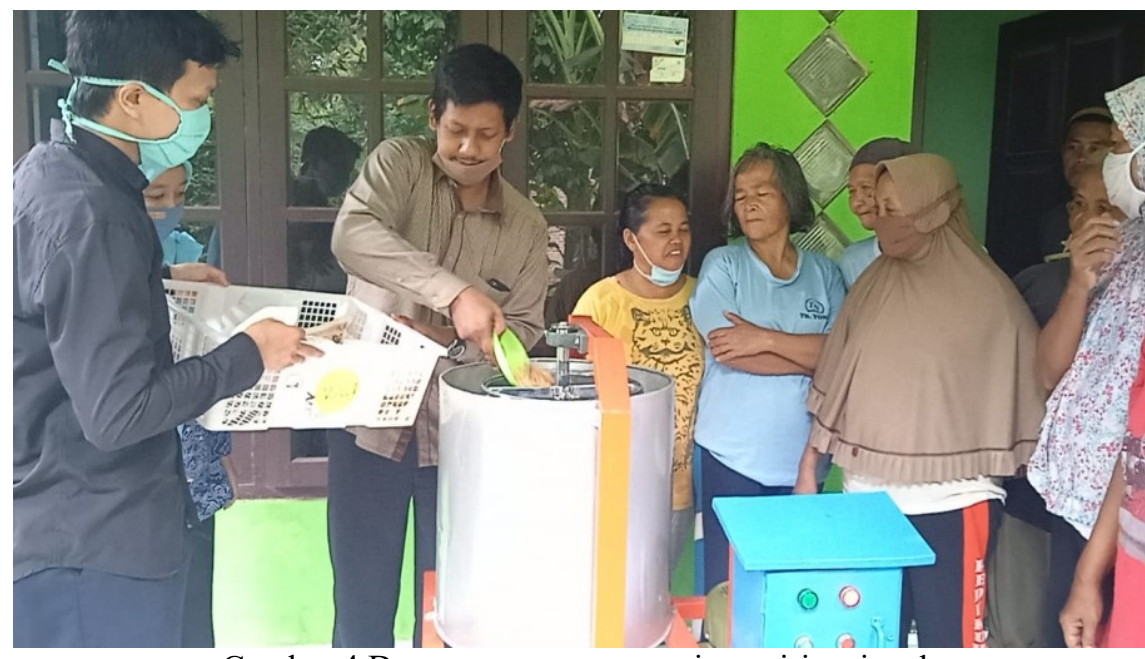

Gambar 4 Demo penggunaan mesin peniris minyak

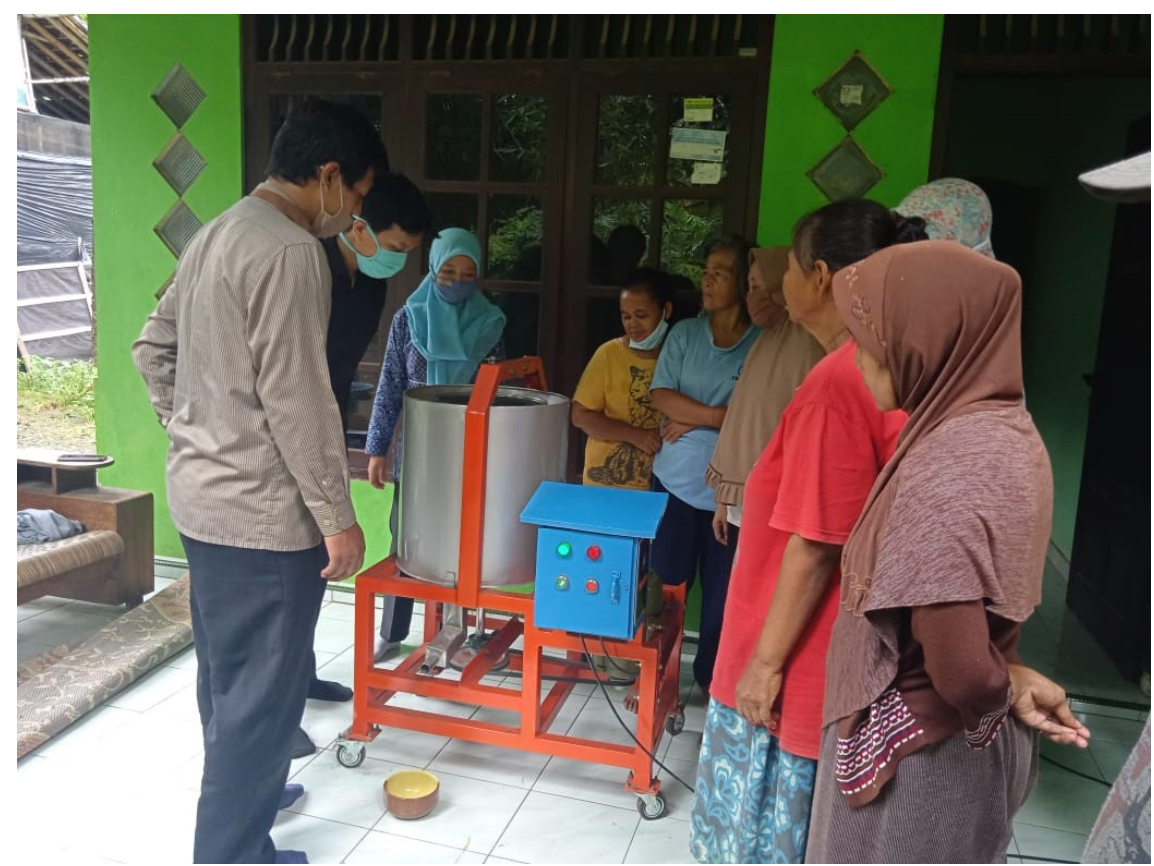

Gambar 5 Proses penirisan minyak dengan mesin peniris

Mesin dioperasikan selama 5 menit dan dimatikan, kemudian keripik jamur diambil. Setelah keripik hasil penirisan ditimbang dan diperoleh berat 4,80 kg. Terjadi penurunan berat sebesar $0.4 \%$. Secara visual terlihat keripik lebih garing dari sebelumnya. Berikut keripik jamur yang telah ditiriskan dengan mesin peniris : 


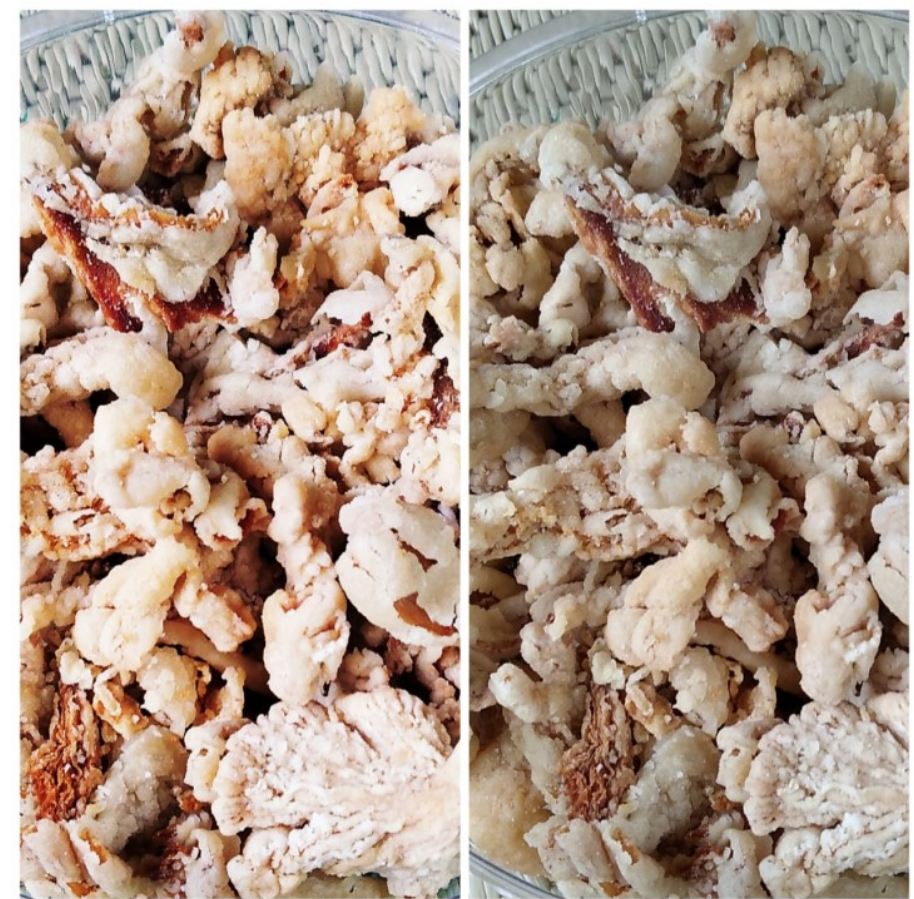

Gambar 6 Keripik jamur sebelum dan sesudah ditiriskan

Warga masyarakat terlihat antusias dengan materi yang diberikan. Hal ini terlihat beberapa masyarakat menyampaikan pertanyaan tentang penjelasan detail tentang cara-cara penggunaan alat peniris minyak. Kegiatan diakhiri dengan penyerahan alat kepada kelompok tani Pesona Jamur.

\subsection{Kesimpulan}

\section{KESIMPULAN DAN SARAN}

Pelatihan dan penyerahan alat peniris minyak yang dilaksanakan pada tanggal 14 januari 2021 dihadiri oleh kelompok tani Pesona Jamur ini berlangsung dengan baik dan lancar. Terlihat antusiasme masyarakat untuk menambah pengetahuan tentang teknologi tepat guna untuk meningkatkan produktifitas jamur. Hal ini terlihat beberapa masyarakat menyampaikan pertanyaan tentang penjelasan detail tentang alat tersebut.

\subsection{Saran}

Perlunya dilakukan penelusuran pustaka yang lebih lanjut tentang teknologi tepat guna, alat peniris minyak, baik kelebihan maupun kekurangannya sehingga didapatkan hasil yang lebih efektif dan efisien.

\section{DAFTAR PUSTAKA}

[1] Andi Resky Ariyani Paramitha. 2012. Studi Kualitas Minyak Makanan Gorengan pada Penggunaan Minyak Goreng Berulang. Universitas Hasanuddin. Makassar.

[2] Wijana, S. Arif, H. \&Nur H. 2005. Teknopangan: Mengolah Minyak Goreng Bekas, Penerbit Trubus Agrisarana, Surabaya. 
[3] Anonim, 2012b. http://anekamesin.com/centrifuge-spinner.html diakses 15 Februari 2021

[4] Romadloni, B.S. 2012. Perancangan mesin peniris minyak pada kacang telur. Yogyakarta: Universitas Negri Yogyakarta.

[5] Dewa, Rengga Permana., Gilang Maulana, Prima Tri Ananda dan Estu Bagus Djatining., 2020. Mesin Pemisah Kandungan Minyak Serbaguna. IST Akprind. Yogyakarta. 